\title{
Challenges in re-designing operations and jobs to embody Al and robotics in services. Findings from a case in the hospitality industry
}

\author{
Erica Mingotto $^{1}$ (D) Federica Montaguti ${ }^{2} \cdot$ Michele Tamma $^{1}$ \\ Received: 30 December 2019 / Accepted: 4 September 2020 / Published online: 21 September 2020 \\ (C) The Author(s) 2020
}

\begin{abstract}
The adoption of artificial intelligence (AI) and service robots in the tourism industry for frontline service automation is generating a growing interest. Although there is a fairly large body of literature about this research field, the impacts on the service encounter need to be further investigated. The paper presents an action research project that led to employ the humanoid robot "Pepper", equipped with a supervised machine-learning AI system, at the reception of an Italian hotel to provide information to clients. This allowed to explore the role played by this agent and the effects on the changing role taken by frontline employees (FLE) and customers. Findings show that this technology can act as an augmentation force and that FLEs' role can evolve mainly into that of enabler - of the customers and of technology -, innovator and coordinator, while customers may take above all the role of enabler of the technology. The study also contributes to introduce the new role of "AI supervisor" among FLEs.
\end{abstract}

Keywords AI $\cdot$ Service robots $\cdot$ Service management $\cdot$ Operations $\cdot$ Hospitality $\cdot$ Jobs

JEL classification $\mathrm{O} 33$

\section{Introduction}

The development of artificial intelligence (AI) and the enhancement of robotics, together with a stronger digital connectivity, impact all business sectors, including services ( $\mathrm{Li}$ et al. 2019; Makridakis 2017). Companies adopt these advanced and smart technologies in order to improve operation

This article is part of the Topical Collection on Artificial Intelligence (AI) and Robotics in Travel, Toursim and Leisure

Responsible Editor: Ulrike Gretzel

Erica Mingotto

ericamin@unive.it

Federica Montaguti

fedem@unive.it

Michele Tamma

tamma@unive.it

1 Ca' Foscari University - Department of Management, Cannaregio 873, 30121, 0412348709 Venice, Italy

2 CISET - Ca' Foscari University, Palazzo San Paolo - Riviera Santa Margherita 76, 31100 Treviso, Italy processes, minimize costs, enrich customer experiences or propose new ones (Ivanov and Webster 2017). Indeed, the technological dimension can be considered one of the components of service innovation (Den Hertog et al. 2010). These technologies have become a common topic also in the travel and tourism industry, where they are generating a growing interest and, at the same time, a kind of concern about the disruptive effects they are having on customer experience, business processes and business models (Lam and Law 2019).

There is already a fairly large body of literature about this research field, also regarding tourism. Studies have investigated the phenomenon from several and interrelated perspectives and seven main research domains can be identified (Ivanov et al. (2019): 1) robot design (functionality, mobility, appearance); 2) human domain, concerned with both consumers' and employees' attitudes, reactions, roles, etc.; 3) robot manufacture (hardware and software); 4) functions in tourism businesses, such as marketing, operations, etc.; 5) servicescape; 6) external environment, in terms of legal, economic, social etc. aspects; 7) education, training and research institutions.

Because of the rapid and continuous evolution of these technologies and the complexity of the disruptive effects, the impact 
on the way the service is provided and delivered - and also perceived by customers - remains one crucial issue to be further investigated. Further research contributions are needed in the field of customers' and employees' attitude; of the changing roles that they may take in the service encounter; of service design; of impacts on processes, operations, jobs and organisational redesigning; of employees' training (De Keyser et al. 2019; Murphy et al. 2017). However, many of these research areas can be effectively investigated through field studies based on the active involvement of companies and their staff, relying on their support and willingness to be studied and to share their strategies (Ivanov et al. 2019). Nevertheless, while many conceptual papers have been produced in this area, empirical research seem to be less developed and research methods such as action research and projective techniques have not yet been applied (Ivanov et al. 2019).

The present paper would like to offer a contribution, particularly answering the lack of empirical studies. Indeed, the study is based on a recent one-year action research project carried out by the authors in order to support the employment of a humanoid social service robot, equipped with a supervised machine-learning AI system, at the reception of an Italian resort with the task of providing information to clients. The project was not conceived as an experiment but was a real investment by the hotel and the software development business involved. A constant field work side by side with the company managers and employees was implemented in order to support them in the adoption process. Regular observation of operations, meetings and interviews with the staff and with the clients were set in order to monitor changes on operations and tasks. In particular, the project allowed to explore the changing roles in service encounters that frontline employees (FLEs) and customers may take as a result of the implementation of AI and service robots. This issue not only emerged to the authors as one on the most felt questions by the partner companies and their staff from the beginning of the field work, but it has also been documented in the literature by several conceptual studies as a crucial topic when it comes to investigate the impacts on the processes of frontline services (Bowen 2016; De Keyser et al. 2019; Ivanov and Webster 2017; Ivanov and Webster 2019c, 2019d; Larivière et al. 2017). The paper introduces a role for FLEs not studied in the present literature, i.e. the AI supervisor, a role of enabler of technology which not only is new, but appears to be a key one for FLEs access to other roles.

\section{Literature review}

\section{Artificial intelligence and service robots in the travel and tourism industry}

It is firstly important to provide an operating definition of AI, machine learning, service robot. McCarthy, who first introduced the term "AI" in the 1950s, defines it as "the science and engineering of making intelligent machines, especially intelligent computer programs" (McCarthy 2007, in Tussyadiah 2020). AI refers to machines that simulate cognitive functions commonly associated with the human mind, since these machines are able to perform human-like tasks, emblematic of which is the ability to automatically and directly learns from experience - machine learning (Aghaei et al. 2012; Panch et al. 2018). Machine learning can be defined as a subset of AI, where algorithms learn associations of predictive power from examples in given data (Panch et al. 2018). The distinction between supervised and unsupervised machine learning was crucial for the present study. Supervised machine learning - one of the most consolidated areas of AI and applied in the case here presented, refers to computer programmes that learn relations between data inputs and outputs, relying on the analysis of outputs of interest defined by a human supervisor. Unsupervised machine learning does not require external definition of associations of (Panch et al. 2018). However, at the moment most AI technologies are based on "narrow" and "targeted" machine learning systems that perform in a quite constrained environment (Panch et al. 2018), as in the case discussed in this paper.

Robots are defined as physical devices that are able to perform specific tasks, thanks to a certain degree of autonomy, mobility and sensory capabilities (Murphy et al. 2017; Chen and $\mathrm{Hu}$ 2013). They are distinguished between industrial robots and social service robots, the one adopted in this study. While industrial robots are employed for performing industrial tasks, social service robots are designed to support and service humans by interacting with them and the environment in a natural, user-friendly and socially-compatible way (Ivanov et al. 2017; Pinillos et al. 2016). As a consequence, they may be used also as the interaction counterpart of customers during service encounters (Wirtz et al. 2018; Kuo et al. 2017). Service robots can be differentiated according to several attributes: their representation (physical robot, as Pepper, or virtual, as Alexa), anthropomorphism (humanoid or non-humanoid robot) and the tasks they can perform (cognitive-analytical tasks and emotional-social tasks) (De Keyser et al. 2019; Wirtz et al. 2018). The efficacy of a social service robot depends on three levels of development: hardware, i.e. the body of the machine, its sensors and the movement system (actuators); functionality, i.e. the software which enables functions such as visual and voice recognition, dialogue, mobility, knowledge representation of mind models; and service, i.e. the tasks that the business assigns to the robot in order to create and deliver added value to the customers (Kuo et al. 2017).

Considering in particular robots employed in service and tourism companies, their acceptance by the customers and the human-machine interaction positively depend on a combination of factors. Some of these refer to the user himself, such as his attitude towards machines, his acknowledgement of their 
advantages, his past experience with technologies (Ivanov et al. 2018). Other factors refer to the robot, i.e. its embodiment and its anthropomorphic characteristics, perceived intelligence and perceived security (Ivanov et al. 2018; Murphy et al. 2019; Qiu et al. 2019; Tung and Au 2018; Tung and Law 2017; Tussyadiah and Park 2018). Consumers are more receptive towards robots with animated features but they could be not always inclined towards humanlike robots (Yu 2019). Indeed, the Uncanny Valley theory (Mori 1970) suggests that as robots become more human-like, users' reaction tend to be positive until they perceive them as too bizarre, weird or creepy. The customer-employee rapport building is crucial for mediating the relationship between robot attributes and consumers' reaction (Qiu et al. 2019) and the kind of tasks performed by the robot is an important factor in customers' acceptance (Ivanov et al. 2018). Greater approval is shown for housekeeping activities, information provision, processing of bookings, payments and documents, and item delivery (Ivanov and Webster 2019a, 2019b; Ivanov et al. 2018).

The rapid technological evolution is leading also in the service industry to the development of applications showing great potential that would have been unthinkable until recently (Ivanov et al. 2017; Wirtz et al. 2018). Although the diffusion of these advanced technologies in the tourism industry is still low (Ivanov et al. 2019), machines powered by AI and robotic systems have started to be implemented in recent years by tourism businesses (from hospitality to airports, from airline companies to restaurants, from museums and amusement parks to information centres) in multiple daily operations in order to support service innovation and automation (Collins et al. 2017; Ivanov 2019; Ivanov and Webster 2017; Ivanov et al. 2017; Li et al. 2019; Makridakis 2017; Tung and Law 2017). Businesses have been automating operations for a long time in order to increase productivity and cost efficiency (Buhalis and Main 1998; Ivanov et al. 2017; Lam and Law 2019). However, the potential of AI, digitization and robotics may further improve and accelerate the automation of processes traditionally owned by FLEs, by involving new areas of business operations and then significantly altering the interplay between the organization and the customers (Larivière et al. 2017).

The reasons why tourism businesses look with great interest to the adoption of $\mathrm{AI}$ and robotics are the opportunity: a) to improve efficacy and efficiency, since these technologies could work longer than humans and perform their work more correctly and in a timely manner (Dogan and Vatan 2019; Ivanov 2019; Ivanov and Webster 2017); b) to save labour costs, substituting or supporting employees, relieving them from manual, repetitive and tedious tasks and allowing them to dedicate to more challenging and creative activities; c) to improve service quality and customers' experiences, by introducing new attractive, funny and engaging ways for delivering services (Ivanov 2019; Ivanov and Webster 2017).
Regarding this last aspect, some researchers suggest that in some cases consumers tend to co-create new experiences, by proactively interacting with robots for developing a certain level of "relationship" with them (Tung and Au 2018).

However, the application of systems based on AI and social robots has to be limited for the moment to quite structured settings and it implies some significant costs, which often are not considered enough by tourism businesses: on the one hand, financial costs linked to acquisition, installation, maintenance and update of the technology and to the hiring of specialists to manage it and to the training of the staff; on the other, non-financial costs, in particular those connected to the resistance of employees (Ivanov 2019; Ivanov and Webster 2017), who could be frightened and psychologically stressed (Li et al. 2019) by these disruptive changes and could refuse to use technology. Together with employees' resistance, implicit costs can also arise from customers' resistance (Ivanov 2019; Ivanov and Webster 2017). Although technological innovation is adopted to improve customer experience, this outcome cannot be taken for granted since customers expect some degree of effort to learn how to use technological devices and, if this is perceived too difficult, they might give up (Ciuchita et al. 2019).

New emerging technologies, such as AI and service robots, have great potential in terms of productivity improvement, service quality and development of new consumers' experience; however, they are not yet perfect and capable of doing everything. Companies are required to adopt them carefully, by making an in-depth evaluation of benefits and costs. An extreme resistance towards these advanced technologies but also an excessive enthusiasm are both to be avoided (Ivanov and Webster 2019a, 2019b, 2019c, 2019d).

\section{The technology adoption process in service and tourism companies}

The adoption of systems based on AI and social robots may bring significant challenges to service and tourism businesses, as it modifies the ways in which the service is delivered and experienced, and thus the relationship between customers and providers and even the roles of employees (and in particular FLEs) and customers (Bolton et al. 2018; De Keyser et al. 2019; Ivanov 2019; Ivanov and Webster 2019c; Larivière et al. 2017; Li et al. 2019). van Doorn et al. (2017), discussing the technology infusion in frontline experiences, introduce the new concept of "automated social presence" (ASP), referring to the ability of the technology to effectively engage consumers in significant social encounters. In this sense, the technology able to act on this social level becomes a real social agent, like FLEs, other staff members and/or other customers.

Since these technologies can change the way companies operate, compete and cooperate (Ivanov 2019) and affect both employees and customers (Ivanov and Webster 2019c), a 
crucial issue to investigate is how companies can effectively manage the adoption process. The literature review seems to show that relatively few empirical studies focus on automation and innovation in the service and tourism industry through new advanced technologies (not only AI and robots), with particular reference to the adoption processes undertaken by the company and to the implications on the service encounter.

Some studies, which investigated the implementation of radio frequency identification (Cobos et al. 2016) or of CRM (Cruz-Jesus et al. 2019) in the service companies from an organizational perspective, explain that the technology adoption process goes through several steps, such as knowledge, persuasion/evaluation, decision, implementation and confirmation/routinization.

Other studies, which explored technology adoption for marketing automation, underline that, when a new technology is included in the business environment, managing the changes on the organisational processes is crucial in order to ensure the automation success (Järvinen and Taiminen 2016; Murphy 2018; Speier and Venkatesh 2002).

Focusing in particular on service innovation and automation through $\mathrm{AI}$ and service robots, the literature underlines that the implementation of these innovative technologies requires an in-depth analysis of costs and benefits and of the service delivery processes; the re-engineering of entire activities, processes and structures; the alignment of strategies and resources such as people (including customers), mind-set and leadership, so that the technological toolset is embedded into day-to day operations and becomes part of the organization (Ivanov and Webster 2017; Ivanov and Webster 2019a, 2019b, 2019c, 2019d; Kuo et al. 2017; Lam and Law 2019).

The adoption process of such kind of digital and technological systems requires efforts both on the part of managers and on the part of employees, since a common understanding of the new organizational context is needed in order for the right skill-sets and mind-sets to be developed and new revised operations and practices to be put in place. It is a complex organizational learning situation, in which people have to learn new skills to face new challenges but, first of all, have to be aware that they need more knowledge and be ready to learn (Lam and Law 2019).

One of the most debated topics about the effects of robotics and AI technologies on organizations is the replacement of human workforce and, in connection to this, the changes in job profiles and in the well-established working relationships among employees and between employees and managers ( $\mathrm{Li}$ et al. 2019). The introduction of these machines may negatively affect the employees' sense of workplace belonging and dedication, unless organizational support is provided, for instance through internal training programs, including soft skills development (Li et al. 2019).

Since different combinations of automated and human social presence in the frontlines can be configured (van Doorn et al. 2017), managing the adoption process means firstly to define the roles that technology can play in the service encounter. It emerged that it does not necessarily have a "substitution" effect. Indeed, within the conceptual frameworks developed by Marinova et al. 2017, Larivière et al. 2017 and then by De Keyser et al. 2019, technology can act as a substitution force, in particular when FLEs no longer take an active part in the service encounter; it can be assumed that modern technologies may, in a way, also replace the customer, by making some decisions on his behalf (De Keyser et al. 2019; Larivière et al. 2017; Marinova et al. 2017). However, technology can also act as an augmentation force when it assists and complements human actors - both employees and customers - to better perform their tasks in the service encounter (De Keyser et al. 2019; Larivière et al. 2017; Marinova et al. 2017), or it can become a network facilitator when it is used to connect different human and technological entities in the service encounter (Larivière et al. 2017). The augmentation and substitution force have been clearly studied and attributed to social robots and AI also by Ivanov and Wester (Ivanov and Webster 2019d).

Another important question concerns what new roles FLEs and customers will play. Indeed, as a result of the role assigned to the technology, both employees and customers may take one or more transformed roles. The frameworks developed by Bowen (2016) and Larivière et al. (2017) explain that they can become: enabler (for example when employees support customers in using the technology; or when customers, with their input, enable the technology to perform its tasks); innovator (when they take part in the development and delivery of new services); coordinator (when they are a leading party in managing the relations between the different networks and channels); differentiator (when they directly contribute to customizing the technology and add it unique dimension to). However, if employees and customers are not made aware and thus do not perceive the benefits of performing their new role, they might not perform as needed (Bowen 2016; Larivière et al. 2017). Investigating in particular the adoption of physical and virtual conversational agents in frontline services, De Keyser et al. (2019) underline that more in-depth research is needed in order to investigate which new roles will be dominant for customers and FLEs, also when conversational agents do not substitute employees but work together with them.

During the action research project carried out by the authors the main issues and questions that emerged were of a similar kind, namely the changing role of FLEs and customers, also in relation to the role that the technology would have taken. Therefore, the present paper develops its research questions starting from the last body of literature discussed above about the changing role of 
employees and customers when frontline technologies, and in particular conversational agents empowered by $\mathrm{AI}$ and robots, are adopted in tourism companies.

\section{Methodology}

\section{The project context and the main technical features of the robot and of the Al training}

The study develops within a one-year project carried out by the authors from June 2017 to June 2018, aimed at the adoption by an Italian resort of a humanoid social service robot (the robot "Pepper") equipped with a supervised machine-learning AI system. The resort - which includes two hotels for a total of 400 rooms, one residence, and several services such as a wellness centre, two restaurants, four swimming pools, a golf course, etc. - is part of a small Italian hotel chain and is located in one of the most popular Italian destinations for leisure tourism by the Garda Lake, in Northern Italy.

The robot was meant to be employed at the reception of the resort for answering guests' simple questions, namely by providing information about the hotel services and the destination, in Italian, English and German (i.e. the main languages spoken by the guests of the resort). The decision to adopt the robot was made by the $\mathrm{CEO}$ and the managers of the hotel chain in order to provide guests with another touch-point for asking for information in addition to the FLEs. The latter not only had to check guests in and out, but were also continuously pressed to answer crowds of guests with different needs and requests related to the large number of services offered inside and outside the resort. The aim of the robot adoption was to allow guests to easily and quickly obtain information on simple issues (opening hours, costs, location, of the services) without wasting time, and, at the same time, to "emancipate" FLEs from the repetitive task of answering such questions, and give them time for check-ins/outs, thick/rich interactions and back office work.

The CEO and the managers of the hotel chain and the business in charge of developing the software for the robot and training the AI asked the authors for a scientific support in introducing the new technology and in managing the changes in service encounters and in operations. This, also because both businesses were investing a lot in terms of equipment and work for this innovation, which nobody had previous experience of. Furthermore, this innovation was, for the software developer, the first step in launching a new business, and, for the hotel chain, the first opportunity in re-organising some processes and re-designing the servicescape. For both companies the risk was high and the competitive advantage to be obtained crucial, so they accepted to negotiate access to information, procedures, employees, to receive the help they felt they needed in managing the change.
This immediately appeared to the authors as a research opportunity, and specifically for the investigation of the impact of such technology on frontline processes and jobs. This study is probably an unicum. Although at the time some social robots and AI were starting to be employed at the front office and in other jobs in the service industry, none of these first experiments, to the best of the authors' knowledge, involved an academic approach, and specifically an academic approach different from ones centred on computer science and IT development. Conversely, in case of experiments lead by members of academia the companies were used as an environment for testing the AI/robot, but had no a real commitment/ engagement in the project.

The robot was chosen by the CEO and managers of the hotel company, with the advice of the software developer. It was manufactured by SoftBank Robotics and equipped with microphones, cameras, sensors, gyroscope, wheels, wi-fi connection and a touch screen. It is optimized for human interaction and it is able to a) speak; b) recognize sounds and voices, images, objects and faces; c) analyse the voice tone; d) move its head, arms and back and move in all directions. The interaction with customers occurs mainly through voice recognition and conversation, although some information (such as maps, weather conditions) is also displayed on its touch screen.

The software developers programmed the robot, selected an external AI platform and developed the interface between the robot software and the AI. The AI was based on supervised machine learning and therefore required solid information content as input in order to start learning and later a regular supervision by a human, who has to check if the $\mathrm{AI}$ is understanding and answering correctly and otherwise provide it with correct inputs, and to update the information. Additionally, the AI learns and performs only for the specific task it was trained for. The preliminary information content was developed by the authors by identifying, with the help of the FLEs, the most frequent questions asked by guests and the possible answers. A set of 280 information items (composed of question and answer) was derived and translated in each of the three languages. The basis for the initial AI training was the same for the three languages. However, when the robot began to interact with customers, the information content of each language started to automatically grow with different items, depending on the questions asked by the guests.

\section{Research questions}

The adoption of new advanced technologies - in particular AI and social robots - in a service environment is a complex process. As documented in the literature by several conceptual studies, when it comes to investigate the impact on frontline service processes, an important issue is related to the role taken by the technology and to the changing role of FLEs 
and customers. Indeed, it is strictly connected to other strategic and organizational issues, such as: the reengineering of operations; the redefinition of tasks and job profiles; the development of new skills both by employees and clients; the service encounter redesign (Bowen 2016; De Keyser et al. 2019; Ivanov and Webster 2017; Ivanov and Webster 2019c, 2019d; Larivière et al. 2017).

This emerged as one of the most felt issues by managers and FLEs also in the project under consideration, immediately from the beginning of the field work. The technology, as a new agent in the organisation, could have substituted or enhanced some human jobs or some specific tasks; it could have modified in some way the interaction with consumers. In addition, even if based on advanced and smart systems, the technology would have needed to be managed and supervised by humans. It then emerged that some operations, tasks and roles both of employees and customers could have been changed; the question was how they would have changed and what implications this would have had for the organisation, for example in terms of redesigning operations, developing new skills for employees or "educating" customers. This issue then led to derive the research purpose and the research questions of this study.

Three research questions were identified, starting from the conceptual framework theorised by Bowen (2016); De Keyser et al. (2019), Larivière et al. (2017).

1 Which role do these technologies play in the organization: augmentation, substitution or network facilitator? There was the need to investigate and clarify, at the beginning of the study, the expectations of the hotel company towards the conversational agent and, after its introduction, to what extent this agent was able to act as expected or even better.

2 With respect to frontline employees: a) which changing roles can they take among enabler, innovator, coordinator and differentiator? b) towards whom: the technology and/ or the customer?

3 Which changing roles can customers take among enabler, innovator, coordinator and differentiator?

\section{Research design}

Given the nature of the project, the study was based on a qualitative and descriptive approach and in particular on the action research methodology. Action research is the systemized collection and analysis of data aimed at generating knowledge that enables actions for making change, and is mainly based on focus groups, participant observation and field notes, interviews, diaries and personal logs, questionnaires, and surveys (MacDonald 2012). Action research can be considered a valid tool particularly for operation management, since it allows to face management and operational challenges while simultaneously contributing to knowledge improvement (Coughlan and Coghlan 2002). It was then thought particularly suitable for the present study, since there was the need to balance the research purpose with the requests of both partner companies, who needed a consultancy support.

The tools implemented for this action research were: 1) semi-structured interviews and meetings with managers and/ or executives; 2) analysis of the operations manuals in use before and after the implementation of the technology, and field observations of the actual procedures followed during the FO encounters; 3) participant observation of customers; 4) interviews with customers; 5) analysis of the data recorded by the AI platform during its interaction with customers.

Figure 1 shows the conceptual framework and Table 1a, b describes the main phases of the overall project, the main activities specifically carried out by the authors for the action research and the tools implemented.

With respect to tool 1), meetings and semi-structured interviews involved 3 employees at the company corporate level (the CEO of the hotel chain, the communication and the business development managers); 7 employees of the resort (the GM - General manager, the FO - front office - manager, and 5 FLEs). Interviews and meetings were carried out face-to-face and moderated by researchers. The participants' statements and answers were immediately transcribed and then collated and analysed, as in Cobos et al. (2016) and in Lam and Law (2019). Firstly, all transcripts were read, in order to understand their overall meaning; secondly, significant statements regarding respondents' opinions and beliefs were extracted; finally, the most common important themes were identified. Meetings and interviews were carried out prior to and following the final adoption of the AI. Before the implementation, topics investigated were: a) the main characteristics of the front office, in terms of main processes, operations and tasks (Cobos et al. 2016); b) managers' goals and expectations and frontline employees' attitude toward the robot and the AI. After the AI and robot adoption: c) if and how FO tasks and operations were changed or were expected to change; d) employees' training needs in managing the robot, supervising the AI machine learning and in supporting the customers-machine interaction (De Keyser et al. 2019). Twelve sessions of interviews and meetings were carried out for a total of $40 \mathrm{~h}, 27$ of which after the robot came into operation.

Tool 2) was the analysis and comparison of old and new operations manuals used in the resort before and after the AI adoption, focussing on the description of the main procedures, tasks and job profiles of the FLEs. In conformity with the action research approach adopted, the authors developed, together with the director and the FO manager, new operations manuals.

Regarding tool 3), participant observations were used to investigate customers' interaction with the robot. The observation protocol was designed on the basis of previous studies 
available in the literature about the application of participatory observation for the assessment of a service robot in a hotel environment (Pinillos et al. 2016) and for investigative purposes in other fields (Escuer et al. 2014; Yalowitz and Bronnenkant 2009). The protocol was based on the pen-andpaper system, which prescribes to unobtrusively observe guests and to manually record data on their behaviour. Four categories of variables were chosen to be observed in order to describe and contextualize how guests approach and interact with the robot: a) stopping behaviour: total time of the interaction (minutes and seconds); 2) interaction behaviour: modality (mere observation of the robot, verbal communication, use of the tablet, touching of the robot, other gestures); intensity (number of questions or other kinds of sentences addressed to the robot); perceived emotions (neutrality; surprise; joy; amazement; embarrassment; fear; anger; contempt) (cf. Tussyadiah and Park (2018); 3) situational variables (time, noise, crowding); 4) demographic variables (estimated age, gender, number of adults and children in the party). 22 onehour sessions were carried out by the authors in different days during the two months after the robot introduction and 65 guests were observed, with an average interaction duration of 1:42 min.

With regard to tool 4), the interviews with customers aimed to integrate the findings from the observations. For this reason, the decision was taken to include in the interviews the guests previously observed and to personally interview them - for about $10 \mathrm{~min}$ - shortly after such observation. The questionnaire included mainly closed questions based on a Likert scale from 1 to 7 about the following information categories derived from previous studies about consumers' attitudes towards robots (Ivanov and Webster 2019a, 2019b; Ivanov et al. 2018; Kazandzhieva and Filipova 2019; Murphy et al. 2019; Qiu et al. 2019; Tung and Au 2018; Tung and Law 2017; Tussyadiah and Park 2018): 1) customers' attitude and willingness to talk with a machine and situations in which customers prefer to be assisted by the robot and by humans; 2) user experience (ease of interaction with the robot, satisfaction about the answers received, robot appearance, etc.); 3) level of customers' awareness about the robot/AI and their

Table 1 a. Phases of the overall project $\mathbf{b}$. Activities and tools of the action research carried out during the project

a.

\begin{tabular}{|c|c|c|c|c|c|c|c|c|c|c|c|c|c|}
\hline \multirow{2}{*}{ Phase } & \multicolumn{13}{|c|}{ Months } \\
\hline & Jun17 & Jul17 & Aug17 & Sep17 & Oct17 & Nov17 & Dic17 & Jen18 & Feb18 & Mar18 & Apr18 & May18 & Jun18 \\
\hline $\begin{array}{l}\text { Phase } 0 \\
\text { Knowledge among the actors involve } \\
\text { hotel company, software house, } \\
\text { researchers/authors }\end{array}$ & & & & & & & & & & & & & \\
\hline $\begin{array}{l}\text { Phase } 1 \\
\text { Understanding the context and } \\
\text { preparing the conditions for the robot } \\
\text { development and AI training }\end{array}$ & & & & & & & & & & & & & \\
\hline $\begin{array}{l}\text { Phase } 2 \\
\text { AI training and implementation of the } \\
\text { robot interaction functions }\end{array}$ & & & & & & & & & & & & & \\
\hline $\begin{array}{l}\text { Phase } 3 \\
\text { Introducing the robot in the business } \\
\text { environment and monitoring }\end{array}$ & & & & & & & & & & & & & \\
\hline
\end{tabular}


Table 1 (continued)

b.

\begin{tabular}{|c|c|c|}
\hline Phase & Activities of the action research & Tools of the action research \\
\hline $\begin{array}{l}\text { Phase } 0 \\
\text { Knowledge among the actors involved: hotel } \\
\text { company, software house, researchers/authors }\end{array}$ & - Analysing the literature & - \\
\hline $\begin{array}{l}\text { Phase } 1 \\
\text { Understanding the context and preparing the } \\
\text { conditions for the robot development and AI training }\end{array}$ & $\begin{array}{l}\text { - Analysing the context in which the robot would } \\
\text { have been inserted: characteristics of the resort, } \\
\text { kind of customers, internal organisation } \\
\text { - Mapping the frontline processes and the service } \\
\text { encounter } \\
\text { - Analysing the information most required by the } \\
\text { customers and identifying the information content } \\
\text { for the AI training } \\
\text { - Analysing the employees' information and training } \\
\text { needs about the new technology }\end{array}$ & $\begin{array}{l}\text { - Interviews and meetings with CEO, business } \\
\text { development and communication managers, } \\
\text { director, front office manager, and five FLE } \\
\text { employees (13 hours) } \\
\text { - Existing internal manuals and other information } \\
\text { provided by the hotel though a series of supports } \\
\text { (website, flyers and other materials distributed or } \\
\text { left in the rooms, in house app, etc.) }\end{array}$ \\
\hline $\begin{array}{l}\text { Phase } 2 \\
\text { AI training and implementation of the robot }\end{array}$ & \multicolumn{2}{|c|}{$\begin{array}{l}\text { The activity carried out in this phase is not strictly part of the action research, but the researchers supported } \\
\text { the software developers in designing the dialogue flow for the AI training, on the basis of the information } \\
\text { content that was mapped in the previous phase. }\end{array}$} \\
\hline \multicolumn{3}{|l|}{ interaction functions } \\
\hline $\begin{array}{l}\text { Phase } 3 \\
\text { Introducing the robot in the business environment } \\
\text { and monitoring }\end{array}$ & $\begin{array}{l}\text { - Monitoring the performance of the robot and its AI } \\
\text { in answering and interacting with customers } \\
\text { correctly } \\
\text { - Monitoring the evolving of the AI training } \\
\text { - Supporting the management in revising operations } \\
\text { and job tasks }\end{array}$ & $\begin{array}{l}\text { - Participant observations of customers ( } 22 \text { one-hour } \\
\text { sessions, } 65 \text { guest interactions observed) } \\
\text { - Interviews among customers ( } 30 \text { completed } \\
\text { interviews) } \\
\text { - Interviews, meetings and observation of business } \\
\text { development and communication managers, } \\
\text { director, front office manager, and five FLE } \\
\text { employees ( } 27 \text { hours) } \\
\text { - Data automatically registered by the AI during } \\
\text { guest/robot interaction ( } 41.600 \text { interactions) }\end{array}$ \\
\hline
\end{tabular}

past experiences with such technology. Among the guests observed, 30 customers completed the questionnaire (12 in Italian and 18 in English), i.e. all those who had accepted to be interviewed.

For a better understanding of the customer-machine interaction, attention was paid also to data automatically recorded by the AI during the human-robot interaction and displayed on the user interface (tool 5). Indeed, the AI textually records all interactions between robot and guest, intended as conversations in which the guest pronounces one or more questions or other complete sentences and the robot replies. The AI user interface was set up for displaying all the conversations and their content and for providing summary indicators, such as the number and average length of interactions and the topics of the conversations in association with their occurrence frequency (for example restaurant opening hours, location of the swimming pool, or location of the city centre). This last kind of information was considered in particular in order to identify the most frequent questions asked by customers to the robot during the 41.600 interactions recorded by the $\mathrm{AI}$ in the two months after its introduction.

\section{Findings}

\section{The role of technology}

As for the first research question, i.e. the role of technology, the preliminary interviews and meetings with the CEO and managers highlighted that they expected that the robot could provide basic information to the guests, while the FLEs would have more time to continue assisting guests for more complex services and thick/rich interactions with customers and performing check-in/out and back-office operation. They intended the technology above all as an enhancement of human jobs, although they did not rule out that the machine could eventually perform other frontline tasks in more or less short time, thus partially substituting FLEs.

Findings from the analysis carried out after the robot implementation (from April to June 2018) seem to confirm that the technology has gradually started to act as an augmentation force. In the first few weeks, $41.15 \%$ of the guests observed appeared confused and agitated: they were not able to clearly 
Fig. 1 Conceptual framework (adaptation on De Keyser et al. 2019, Larivière et al. (2017))

\begin{tabular}{|c|c|c|}
\hline \multicolumn{3}{|c|}{ Role of the technology } \\
\hline $\begin{array}{c}\text { Augmentation force } \\
\text { (support for FLE jobs and/or } \\
\text { customers) }\end{array}$ & $\begin{array}{c}\text { Substitution force } \\
\text { (replacing FLEs and/or } \\
\text { customers) }\end{array}$ & $\begin{array}{c}\text { Network facilitator } \\
\text { (enabling connections and } \\
\text { relationships) }\end{array}$ \\
\hline
\end{tabular}

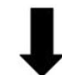

\begin{tabular}{|c|c|c|}
\hline Changing roles of FLEs & Changing roles & Changing roles of customers \\
\hline $\begin{array}{c}\text { Enabler of the customers in learning } \\
\text { how to use the technology } \\
\text { Enabler of the technology in } \\
\text { performing better its tasks }\end{array}$ & Enabler & $\begin{array}{c}\text { Activator of the service encounter } \\
\text { Enabler of the technology in } \\
\text { performing better its tasks }\end{array}$ \\
\hline $\begin{array}{c}\text { - Active agent in developing new } \\
\text { services and/or improving existing } \\
\text { ones }\end{array}$ & Innovator & $\begin{array}{c}\text { "Free consultant" and co-creator } \\
\text { contributing to the development of } \\
\text { new services and/or the } \\
\text { improvement of existing ones }\end{array}$ \\
\hline $\begin{array}{c}\text { Active agent in coordinating and } \\
\text { managing different channels and } \\
\text { relations }\end{array}$ & Coordinator & $\begin{array}{c}\text { Active agent in building } \\
\text { communities between other } \\
\text { customers, the company, etc. }\end{array}$ \\
\hline $\begin{array}{c}\text { Active agent in customizing and } \\
\text { adding a unique dimension to the } \\
\text { technology and the service } \\
\text { encounters }\end{array}$ & Differentiator & $\begin{array}{c}\text { Active agent in customizing and } \\
\text { adding a unique dimension to the } \\
\text { technology and the service } \\
\text { encounters }\end{array}$ \\
\hline
\end{tabular}

understand what the robot's functions were and they mistook it for a gadget; they found it difficult to start the interaction because they had to select the language on the robot touch screen and, according to the data recorded by the AI, they asked noncoherent questions the AI had not been trained for (such as "how old are you?"; "can you dance or sing?"; "can I take a picture with you?"). However, in the following weeks, guests gradually started to recognize the robot as an assistant. This change was the result mainly of two factors: firstly, the AI became more effective in providing correct answers, thanks to its gradual improvement through its machine-learning (from about $51.57 \%$ of exact answers provided by the $\mathrm{AI}$ in the first weeks of April to more than $75.33 \%$ of exact answers at the end of June); secondly, guidance about the robot functions were provided to clients through information panels, and FLEs started to introduce the robot to guests during the check-in operations and to invite them to use it for basic requests of information. Findings showed: an increase in numbers of customers who interact with the robot in a correct and smooth way (from $58.85 \%$ to $88.24 \%$ of guests observed); an increase of consistent questions asked by guests - from $32.96 \%$ to $52.14 \%$; an increase in customers' satisfaction, recorded through questionnaires, from an average value of 1.83 to 4.10 on a scale of 1 (minum) -7 (maximum), and customers' willingness to use again the robot (from an average value of 1.70 to 4.06 ).

Findings showed that the conversational agent is able to fulfil its task, i.e. supporting and working in conjunction with FLEs so as to improve the quality of the service encounter. The technology here implemented, if further programmed, has the potential to perform other tasks as well (for example check-in/out), but at present it is still too limited to engage in more complex interactions with the guests and entirely substitute FLEs.

\section{The changing role of employees}

As for the second research question, i.e. the evolving role of the FLEs, the comparison between operation processes before and after the robot introduction clearly highlights how the FLEs' role has changed, and particularly the role and tasks of some among the FO executives chosen to be the AI training supervisors.

\section{Enabler towards customer and technology}

Before the beginning of the project FLEs had no role in supporting customers in using technology. The analysis of the procedures and the interviews explained that no technology, except the basic back-office PMS, was used specifically for service encounters. This is not to say the employees and managers did not use any technology in their work. The hotel was provided with a typical infrastructure including a PMS, channel managers, revenue management systems, etc. However, these tools were not meant for the customer to use directly or as a mediation in the relationship between the customer and the front office employees or any other relationship between the hotel personnel and the customers. The only technology, website aside, developed for the customers was an in-house app, with respect to which, however, receptionists were not specifically required to provide assistance, and which the clients did not like to use. At the hotel, service frontline experiences were therefore low in automated social presence and high in human social presence (van Doorn et al. 2017).

Contemporary to the introduction of the robot, the interviews with the managers and the FLEs highlighted the need for a specific training on the basics of the $\mathrm{AI} /$ robot use and its 
limits. A specific training was devised and delivered by the authors, not only on technical characteristics but also on how to interact with it the robot, the kind of information the AI could provide, and the need for it to be further trained and monitored. FLEs were specifically encouraged to interact with the robot themselves and to ask clients to do the same. Together with the GM and the FO manager, a specific entry on interaction procedure and its technical basics was added to the FO operation manual. Interviews showed how this training was felt as essential by the software developers, to ensure an effective and autonomous functioning of the robot and AI. Not only the developers underlined the need for some training, but specifically for a training centered on involving FLEs role towards the robot, the AI and the customers, more than on technical aspects (how to switch it on, clean it, check its wifi connection or audio system, how to access the API and check the training, etc.). The developers clearly stated that they realized that the key aspect to make the project a success was not only for the technology to run smoothly, but also to provide the maximum attention to the AI training within the hotel, and to set the conditions to encourage customers to use it as much as possible. It has to be recalled that, at the time the study was conducted, this was the first implementation for the software developers, and one of the first in general, so a failure in the activity of this robot/AI) would have compromised a whole new possibility for business development for them. The hotel management, since the project implied the introduction of an advanced technology in the area of service encounters where there was none before, agreed on it. The analyses of the processes and procedures before the $\mathrm{AI}$ introduction and the knowledge of how the robot/AI worked, led the authors to a similar conclusion, and all the parties agreed on the need for specific training.

This being more their expertise area, the authors were the main responsible for the design and delivery of the training, but content and approach were all agreed upon and developed together with the parties involved.

When the robot had been working for a month, it emerged a need to further reinforce the "message" provided during the training to FLEs. The supervision of the hotel managers on how the customers were reacting and interacting with the robot/AI led them to conclude that there could be improvements in the level of engagement and interaction between the robot and the customers.

The developers and researchers' check on the AI work confirmed that it was answering correctly to the majority of the questions (from about $51.57 \%$ of exact answers provided by the $\mathrm{AI}$ in the first weeks of April to more than $75.33 \%$ of exact answers at the end of June) but the interactions were short and superficial. On this basis, further interviews with the FLEs and managers, in combination with the participant observation, led the researchers, the FO manager and the GM to agree that the new role of the FLEs had to be made more apparent - for themselves and for their colleagues - and that an intervention on the procedures could effectively encourage the customers and compel the employees to become enablers towards the technology. Specifically, it was decided to change the existing check-in procedure, and, more in detail, to shorten the information about the hotel given during the final steps of the check-in, instead introducing a sentence that invited the tourist to "ask for further information you may need later and in the next days to Robby, our robot concierge".

The training, the redesign of the procedures and then of the manuals clearly highlighted the role of the FLEs as enablers, who support the customers on how to interact with and what to ask to the $\mathrm{AI} /$ robot. This confirms the initial hypothesis that the introduction of the AI would lead the FLEs to assume an enabler role, as also supposed by Larivière et al. (2017).

In addition, findings highlighted a far more important change in the role of some of the FLEs. A completely new one emerged: the "AI supervisor". The need to create this new role came from a specific request of the ICT company that worked on the interface between the AI and the robot software, as the software developers underlined that, for the sustainability of the project, there was the need to identify someone within the hotel staff who would be in charge of training the $\mathrm{AI}$ in the future, since the developers did not plan to do this themselves and also stressed how this would speed up the process in any case. The hotel management agreed with the request, and identified the supervisors in some FLEs.

The analysis of the kind of activities and skills needed to train the AI confirmed this need. The API was in fact very user friendly and did not require someone with a knowledge of computer science, but rather with a wide knowledge of the hotel services, the destination, the needs and tone of language preferred by the clients and defined by the brand, etc. Managers, developers and researchers agreed at that point that those skills and knowledge were typical of the FLEs, and that someone among them - in particular the more flexible, openminded and technology-ready FLEs - should be given the task to supervise the AI training and update it, in order to allow the $\mathrm{AI}$ and the robot to correctly interact with the clients. 4 supervisors were identified by the hotel management, one per each of the languages the AI has to use plus the FO manager. It is important to underline that none of the people involved had a supervising role of any kind before being named "AI supervisor", apart from the FO manager, and that the interaction of these people with technology until that moment was limited to the use of the desk computer, of basic suites and of the PMS.

All the AI supervisors received a specific training for the new tasks, which also encouraged them to observe the customers-robot interaction whenever possible, in order to improve the information level and solve or prevent possible misunderstanding in the human-machine interactions. Another specific manual for the "AI supervisors" was designed and written, and included instructions on the use of 
API and on the number of times per week they were to work on it (three-four times a week in the running-in phase and then at least once a week). A specific tool (Trello TM) and a procedure on how to communicate the updating of information were also defined.

As a consequence, the FLEs acting as "AI supervisor" qualify as enablers, although not only towards the customers, but also towards the technology. By training it, and keeping it up to date, the supervisors support the technology in understanding clients, learning about their needs, and interacting with them. This role is specifically related to a machine that learns how to interact and changes accordingly by adapting to humans. With all the traditional technologies, instead, once the mechanism has been defined by the developers, the machine is not easily modifiable and the user must adapt to it. In this case, it is only possible to enable people to understand the technology, while in the case of AI the ability required is that of enabling the technology to understand the people it works with.

\section{Innovator}

The researchers had assumed that the time and attention resources set free by the introduction of AI could be directed towards the role of innovator. However, in the two months following the robot introduction, the corporate and hotel management seemed reluctant to explore and even less recognise this role, so no change was made in the job description or in the tasks assigned to FLEs. One the one hand, the management preferred that FLEs focussed on back-office activities; on the other, given the pioneering nature of the project, the management was adapting to a development of the FLEs role that was not entirely expected. Indeed, if the role of enabler to support clients was foreseen, the commitment required by the role of enabler towards technology was difficult to be anticipated, since the effectiveness of the traditional technologies used until that moment (not for service encounters though, as already said) depended entirely from the IT developers. However, during interviews and meetings one month after the robot introduction, the new AI supervisors showed a "natural" inclination in proposing improvements to support the clients-AI interaction and more generally the customers' relationships with various devices provided by the resort. As said, only the FO mangers, among the "AI supervisors", already had a responsibility role. However, the interviews conducted before introducing the robot showed that, beforehand, not even the FO manager had a role of innovator with respect to technology in general, and, to the inexistent service encounters technology in particular: of this the chain staff and the hotel GM were in charge.

\section{Differentiator}

What discussed about the innovator role applies to the differentiator as well. Although encouraged to reflect on it, the managers were prone to delay this transformation. Differently from what happened with the innovation aspects, however, also the AI supervisors did not advance any proposal on how they could change their behaviour and skills to make the difference for the client.

\section{Coordinator}

The management again was not ready to recognise this role. The AI supervisors, however, although not formally, assumed the role of coordinators as a "spin-off" of their role of technology enablers. By deciding which information has to be provided to guests by the robot and which information by FLEs (e.g. can the clients be informed about the golf course prices by the robot or do they need to go to the FO, or directly to the golf course personnel; etc.), the supervisors de facto direct the clients to this or that area for a specific service encounter, define when this encounters should be technology supported or not, and partially instruct the level of coproduction of the client. Although the information to be included in the AI and the way in which to answer some questions from the customer are agreed with the GM and other managers, the supervisor has the possibility to suggest and discuss coordination aspects not allowed to other FLEs, e.g. in the specific case the supervisor discussed at different level the opportunity the AI provides a full information on some services or it answers to ask directly at the reception desk. Favouring one solution over the other one depends on the complexity and update rate of the information and on the fact that the robot could be much more effective in providing some hints, having the possibility to display on its screen maps, website, etc. The decision regarding what kind of information was to be provided on the printed materials is not only an example of how the supervisor contributed in trying to improve the customer experience, but also of how he contributed in the design of service encounters.

\section{The changing role of customers}

Regarding the third research question, findings from the study showed that also the transformed role taken by customers qualifies as enabler of the technology. First of all, the encounter provided by the robot can only happen through an active input from the guests (as underlined by Larivière et al. (2017), who can decide whether to ask to the robot or to a human employee and - if they opt for the robot - who have to enable the interaction, by selecting the language on the tablet (among the guests observed, $82.30 \%$ select the language and start to 
interact with the robot, while the others just watch it, without enabling the conversation).

Customers become enabler of the technology also in the sense that they actively contribute to the AI training. However, guests became fully aware of this role, only when FLEs and the information panels explained to them that their contribution in interacting with the machine was precious for improving the AI effectiveness and then the user experience. According to the interviews, customers seem to have positively accepted this role, since all respondents were eager to actively "cooperate".

Due to the limited period in which the effects of the robot adoption on customers' experience were observed, findings are not sufficient to clearly identify other possible changing roles taken by customers. However, we may assume that customers could act also as a kind of differentiator of the service encounter, since, by interacting with the machine and actively giving inputs for the AI training, they may progressively shape and customise the information environment of the AI according to their specific requests and needs. They may contribute to differentiate the AI from its "initial version" and in general from a more standardized solution that also other similar competitors could adopt.

\section{Discussion and conclusion}

The merit of this study largely lies in the fact that it is based on a concrete real life case and on the action research methodology, that have allowed the authors to directly observe and assist the company for a whole year, investigating what it means to really incorporate an AI-based technology within a service business environment. The adoption of a robot/AI was not conceived as an experiment but as a real asset for the businesses involved, showing strategic and operational issues. The project developed thanks to a strong cooperation between the researchers, the software developers, hotel managers and employers and gave the researchers the opportunity to monitor the whole process and the critical aspects.

\section{Contribution and theoretical implications}

The first contribution of this paper to the studies on service robots and $\mathrm{AI}$ in the hospitality and service industry is to fill the gap in empirical research focussed on companies, staff, and organizational re-design, and based on research methods - such as action research - with a strict cooperation with the companies themselves (Ivanov et al. 2019). It explores the impact of robots and AI on operations management of hotel companies and specifically how robot and AI change a part of these management procedures. Both questions have been pointed out for future research by Ivanov and Webster (2019a, 2019b, 2019c, 2019d).
Secondly, the case here investigated is a hospitality business that can be considered "representative" of a quite large part of businesses of the hospitality sector. Not a "champion" of cutting edge technologies or an experiment of a big international chain, with easy access to significant financial and human resources, was chosen. This is a small hotel chain, with no more than 13 hotels and a quite experience in the common computer technologies for hospitality management and marketing.

Thirdly, the paper focuses on a situation where a high level of automated social presence combines with a similarly high level of human social presence, a configuration still not much investigated (van Doorn et al. 2017). The introduction of AIbased technology within a service business environment seems not only to change roles, but also to create new roles both for customers and employees. In addition, it seems to need new approaches to be effectively introduced, as they challenge knowledge and practice accumulated with past technologies.

More specifically, in reference to the first research question - which role these technologies act in the organization: augmentation, substitution or network facilitator - the present study shows that the conversational agent adopted in the resort can qualify as augmentation force, supporting FLEs in assisting guests (Ivanov and Webster 2019d; De Keyser et al. 2019). This role was assigned by the managers when they decided to adopt the technology and the AI was trained accordingly, but it was not taken for granted since it needed to be first "accepted" by FLEs and customers. Once the technology was well trained, the interviews showed how the FLEs started to recognise the robot as a support that could relieve them from the task of answering repetitive questions, thus allowing them to dedicate themselves to more complex aspects of their jobs.

Also the customers, once supported and "educated", recognised and accepted what the tasks of the robot were; this confirms other findings in the literature, which showed that information provision is one of the tasks undertaken by robots that has greater customers' approval (Ivanov and Webster 2019a, 2019b; Ivanov et al. 2018).

However, the effort in training the AI and re-designing the roles of employees and customers around it suggests that it is not yet possible for the robot/AI to substitute completely FLEs in a job requiring the management of complex information flows and relationships. The first, less "guided", interactions of the customers with the robot confirm the tendency to anthropomorphize it, expecting human abilities - as suggested by van Doorn et al. (2017), and to actively engage in conversation with the robot to develop a certain level of "relationship" - as suggested in Tung and Au (2018). However, these levels of interaction require the AI the flexibility to span from one to the other cognitive domain and relationship kind - a flexibility that the most used narrow AI kind is still far from achieving. 
Fig. 2 The role of technology and the main changing roles of FLEs and customers

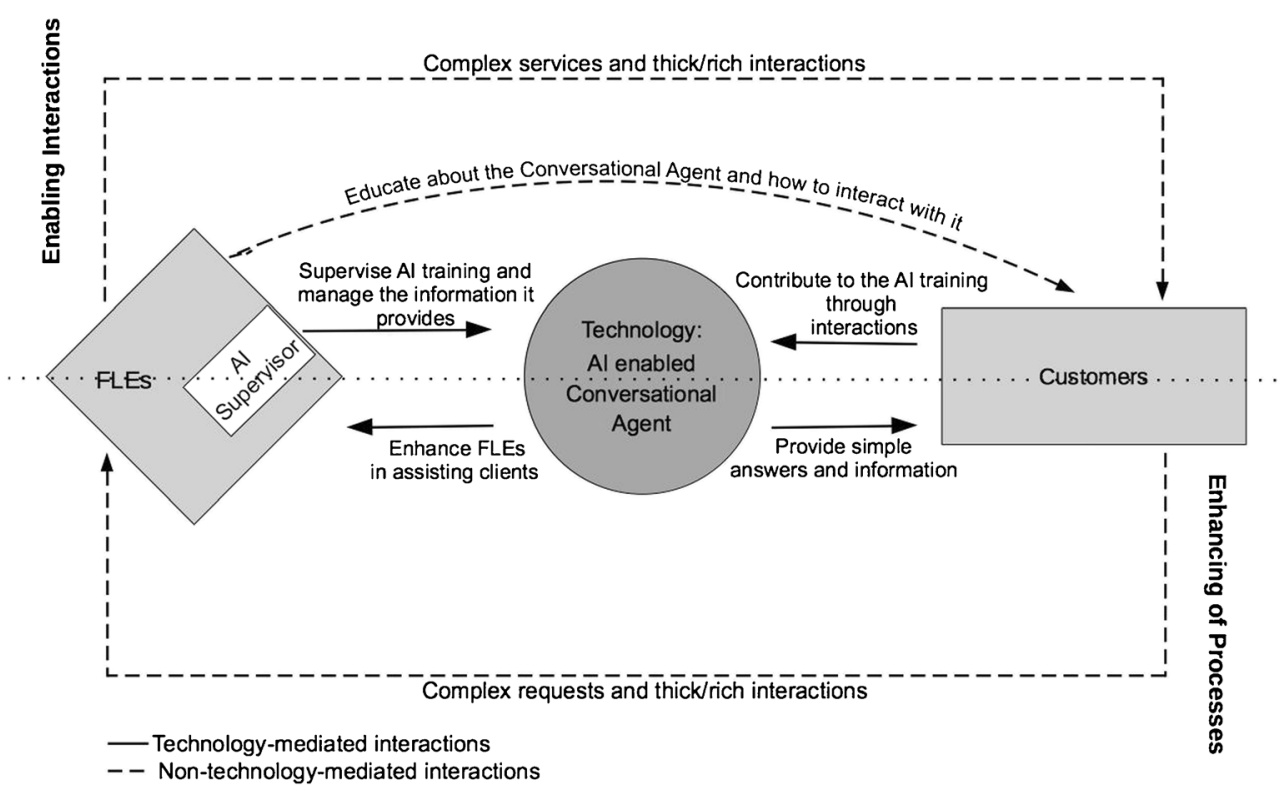

The second research question addressed the role of frontline employees: a) which changing roles can they take among enabler, innovator, coordinator and differentiator? b) towards whom: the customer only, and/or technology? From the theoretical point of view, this study highlights the existence of a role for FLEs that, although hypothesized within this study, was not foreseen or sufficiently investigated in the existing literature on the evolving role of FLEs in front of the infusion of technology in service encounters: the role of the AI supervisor (Bolton et al. 2018; De Keyser et al. 2019; Larivière et al. 2017). This is the most important finding emerging from this study, as it has implications on the other FLEs roles and it is a consequence of the presence of a learning technology supposed to interact with the customer in a natural language and way, providing a service experience where customers are engaged by technology on a social level (van Doorn et al. 2017). The supervisor is essential in ensuring a smooth and effective service encounter between the robot and the client, but a poor supervision and training of personnel is a high risk both for the technology itself and for the overall success of its introduction.

Not only does the study introduce this role, but, in particular for FLEs, it also suggests how the "AI supervisor" might be a key role to access those of coordinator, innovator, etc. Indeed, the role of enabler towards the customer (Larivière et al. 2017) is fully confirmed for all the FLEs by this case, as the role was formally recognised and the procedures changed. The change of the procedure and the revision of the manual gave a chance also to explore how the service operations manual have been/can be updated as a consequence of the "robotisation" of some FO activities (Ivanov 2019).
The other roles of FLEs envisaged in the literature - innovator, coordinator and differentiator - seem however mainly accessible to the "AI supervisor". There was no element indicating that the situation and tasks of the other FLEs might change further, since, having "merely" a role of enabler for the customers, they were simply required to acquire some basic knowledge about the robot/AI, and to follow a specific protocol during the check in.

At the same time, a couple of these roles, namely coordinator and innovator, emerged spontaneously, as the AI supervisor, being put in full control of the information and of the AI, was able to suggest how to use it for a better tourist experience, work and information flow, although the management decided not to recognise these other roles. However, the study points out how the fostering of those new roles is not so easy on the management's part. Indeed, Bowen (2016) comments how the coordinator role is the most important, but the less recognized by the managers. The authors are presently studying other cases of conversational agents introduced to support and foster FO and booking/ordering activity in the hospitality industry and restaurants, which seem to confirm the key importance of the "AI supervisor".

The third research question was what changing roles customers can take among enabler, innovator, coordinator and differentiator. The study provides evidence about the changing role of customers, who act as enabler of the technology, not only because it is up to them to give the input to the machine and start the interaction, but also because they actively contribute to the AI machine learning. However, customers became full enablers only after they received information and guidance by the FLEs about the robot functions (it as an assistant and not a gadget or a toy to entertain guests) and the 
way the AI learns. Indeed, once customers had been "educated", they started to interact with the machine as expected by asking questions that were consistent with the tasks the AI was trained for and then by supporting its machine learning. The customer-employee rapport building is important for mediating the relationship between the robot and the customers, as suggested by Qiu et al. (2019).

This accounted role for the customer, as the AI supervisor one, was not foreseen in existing literature (Bolton et al. 2018; De Keyser et al. 2019; Larivière et al. 2017), which does not appear to consider that learning machines are evolving ones, and thus need interaction to do so, differently from the technologies so far known, which, once debugged, are expected to work perfectly from the first interaction.

See Fig. 2 and Table 2 for a synthesis.

\section{Managerial implications}

From the managerial point of view, the study highlights that the success of this kind of automation does not depend only on the selection of the solution (robots and AI) that best fits the company's profile and operating environment. It also strongly depends on the assimilation process (Hasgall and Ahituv 2018) and then on efforts made by the company to reorganise some operations and to re-design customers' and FLEs' roles, also by providing a differentiated training and guidance on how to use, interact and manage the AI system.

The study indicates, however, that managers as well as academics operate on the basis of previous experiences with technologies that, once installed, are fully developed, where the employees or customers are supposed to act within already defined steps. This may lead them to underestimate how much the machine learning systems need in terms of training and attention, and how the employment of these systems requires a re-definition of the employees' role, not only in order to find spaces the technology does not occupy but also simply to allow the system to properly work. This implies that the managers need to be aware of the full implications of the AI adoption in terms of service design, ecosystem, employees' skills and new coordinating needs.

For the managers it might also not be as easy as it seems to rethink FLEs in roles that are far from traditional ones and require specific training. Furthermore, to full exploit the potential of innovation, differentiation, etc. offered by the AI, the managers should probably change the job description and the recruitment criteria. A similar situation might be found in those hotels where the FO desk was cancelled and FLEs were transformed into guest experience executives, who were required to stay in the lobby and interact with the customer: the customers were lost in the lobby as they did not know what they were supposed to do and who they should look for, while the employees were too used to wait for the customers, and so tended not to approach them, or had difficulties to tell new customers from others already checked in (Accor Group and Skift 2019). In this case too customers and employees needed to be instructed and trained for their new roles.

As suggested by Larivière et al. (2017), the study gives evidence that both employees and customers need to update their skills or gain new ones to assume the new roles. From the customer-side perspective, the development of new skills could seem not so challenging, since social robots and conversational systems based on $\mathrm{AI}$ are conceived and designed in order to interact in a user-friendly and socially-compatible way and to understand questions posed in natural language. However, for ensuring a successful interaction, it is essential that clear information is provided to customers not only about the tasks of the machine (what use the machine is meant for and what it is able to answer) but also about how important customers themselves are in contributing to the AI training and development. As suggested by Ciuchita et al. (2019), customers have to be supported in coping with the "innovation", in order to make them more eager and maximise their gains in using the machine.

For FLEs, and in particular for the AI supervisors, specific knowledge and skills have to be provided about the technology adopted in the business (kind of AI and how it works, mechanisms of the supervised machine-learning, robot features, management of the information provided by the machine, etc.) and the main issues related to the interaction with customers. An in-depth knowledge about the organisation and its processes is a pre-requisite condition; this is why it is better to find the AI supervisors among the FO staff, paying however particular attention to those employees with both technology readiness and soft skills (as supposed by Larivière et al. 2017), such as open-mindedness and flexibility.

\section{Limitations}

The present research is an exploratory study based on a specific case and on a project in which the authors were engaged as consultants for the businesses. As a consequence, the cooperation with the researchers might be considered a limitation, as the software developer and the hotel managers and staff, left to their own devices, would have possibly approached the training of the AI and its introduction in a different way. However, needs in terms of procedures, roles, ad skills emerged independently from the researchers, and the fact that some roles were rejected when addressed (innovator, coordinator, etc.) shows how the other partners were not so influenced in their decision making by the researchers' presence.

Another limitation is linked to the fact that the authors, partially also because of a hardware problem that required the robot to be sent to the producer to be repaired, were not able to study the AI introduction for a longer period. 


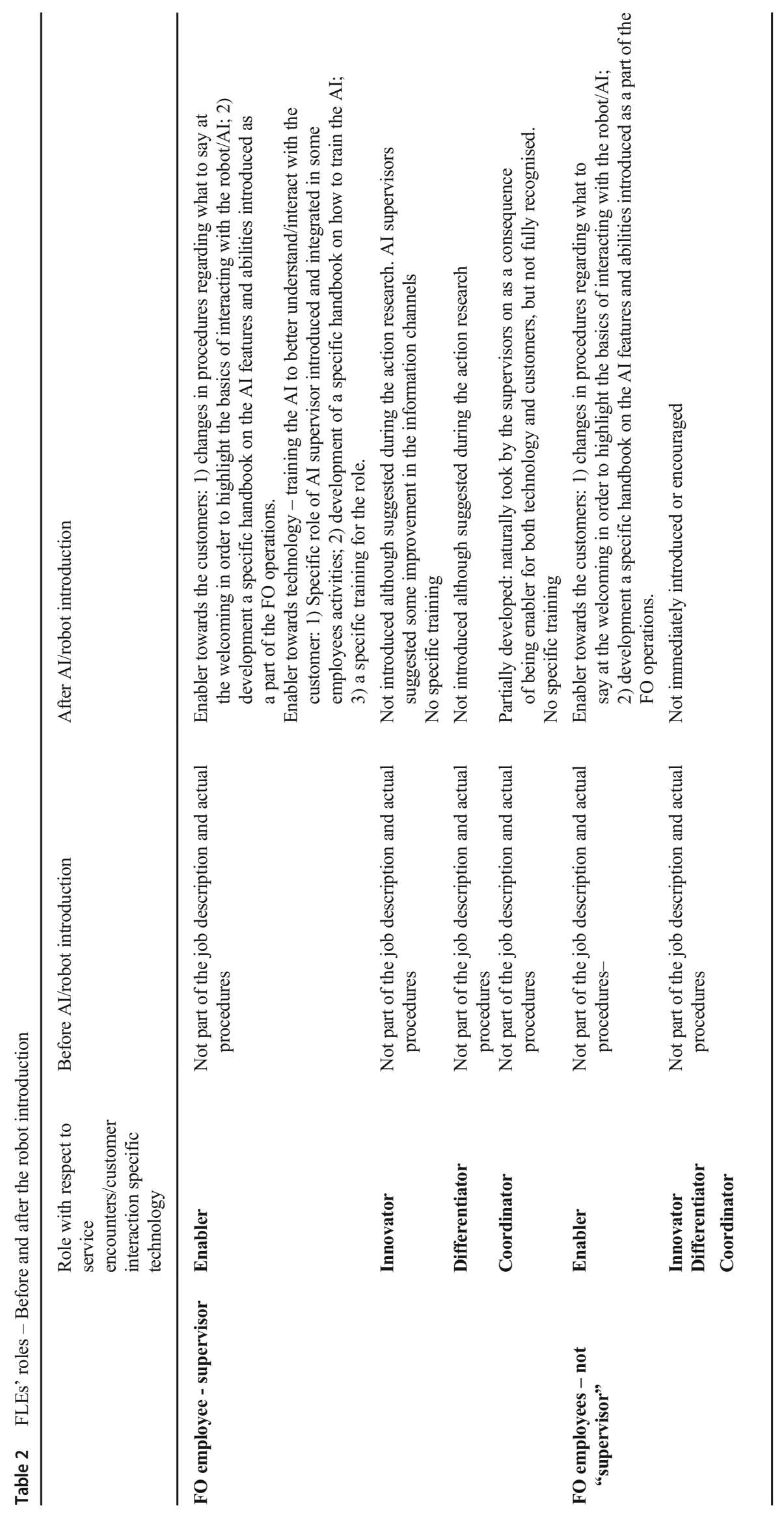


Another issue is that, given the nature of the project, there was the need to balance the main practical needs and requests of the businesses with the research purposes and design. This aspect may be considered a limitation, for example in relation to the low number of interviews to customers, since business managers were not so inclined to disturb guests during their stay. In addition, in order to assess the AI evolving impact on customers' perception and satisfaction, respondents should be the same at the beginning and at the end of the monitoring period. Unfortunately, it was impossible to interview the same customers since respondents were guests who were staying in the hotel at the time the interviews were done and who never came back again during the two-month monitoring period.

In addition, the results of this study need to be validated through further research on other cases, possibly considering differences between large international hotel chains and SMEs and other kind of conversational agents. The very reason that led the decision to adopt this technology in this specific case of a large resort may not have sense in smaller hotels; also, the way of approaching the changes brought by this machine may differ if other typologies of conversational agents are implemented.

\section{Future research}

Although the project allowed an almost unique access to data and observation, it is essential to analyse what happens in cases with no direct support form researchers. The growing of some FLEs into the role of "AI supervisor" that this paper contributes to introduce and integrate to the existing studies needs to be confirmed to exist in other scenarios and environments, also in order to understand if it is always a responsibility of FLEs, or if different choices are possible and what these entail for the employees themselves and the management.

On this note, a first analysis conducted by the authors on other cases seems to indicate that, to avoid the technology failure, the software developer might decide to continue the training of the AI for as long as it works, recruiting staff specifically for this purpose, while FLEs, not involved directly, keep on with their usual tasks. This kind of scenario would then lead the "AI supervisor" role to be externalised. Would that encourage the managers and the software developers to think of a technology that is a substitution instead of an augmentation force? And would that mean a strong standardisation of the service encounters?

Future research should expand considering also the impact determined by other AI devices and not only physical humanoid robots. Indeed, with respect to the customer role, it would be essential to understand if customers' approach and interaction would be different in front of a different support (e.g. chatbot), and if, in this case, their role as enabler, innovator, etc. would be more or less fully developed. Another factor to be explored is the role of customers and employees if the AI supports service encounters that happen before the arrival of the customer at the hotel/destination. In addition, further research should investigate the cases in which multiple devices and conversational agents are adopted in the service encounter at different levels of the customer journey (before booking, onsite, etc.), exploring the relations among devices, and between customers, agents and employees.

Funding Open Access funding provided by Università Ca' Foscari Venezia within the CRUI-CARE Agreement.

Open Access This article is licensed under a Creative Commons Attribution 4.0 International License, which permits use, sharing, adaptation, distribution and reproduction in any medium or format, as long as you give appropriate credit to the original author(s) and the source, provide a link to the Creative Commons licence, and indicate if changes were made. The images or other third party material in this article are included in the article's Creative Commons licence, unless indicated otherwise in a credit line to the material. If material is not included in the article's Creative Commons licence and your intended use is not permitted by statutory regulation or exceeds the permitted use, you will need to obtain permission directly from the copyright holder. To view a copy of this licence, visit http://creativecommons.org/licenses/by/4.0/.

\section{References}

Accor Group and Skift. (2019). The Transformative Role of Design in Hospitality. Retrieved from https://skift.com/2019/06/06/new-skiftreport-the-transformative-role-of-design-in-hospitality/.

Aghaei, S., Nematbakhsh, M. A., \& Farsani, H. K. (2012). Evolution of the world wide web: From WEB 1.0 TO WEB 4.0. International Journal of Web \& Semantic Technology, 3(1), 1-9.

Bolton, R. N., McColl-Kennedy, R. J., Cheung, L., Gallan, A., Orsingher, C., Witell, L., \& Zaki, M. (2018). Customer experience challenges: Bringing together digital, physical and social realms. Journal of Service Management, 29(5), 776-808. https://doi.org/10.1108/ JOSM-04-2018-0113.

Bowen, D. E. (2016). The changing role of employees in service theory and practice: An interdisciplinary view. Human Resource Management Review, 26(1), 4-13. https://doi.org/10.1016/j.hrmr. 2015.09.002.

Buhalis, D., \& Main, H. (1998). Information technology in peripheral small and medium hospitality enterprises: Strategic analysis and critical factors. International Journal of Contemporary Hospitality Management, 10(5), 198-202. https://doi.org/10.1108/ 09596119810227811.

Ciuchita, R., Mahr, D., \& Odekerken-Schröder. (2019). Deal with it: How coping with e-service innovation affects the customer experience. Journal of Business Research, 103, 130-141. https://doi.org/ 10.1016/j.jbusres.2019.05.036.

Chen, Y., \& Hu, H. (2013). Internet of intelligent things and robot as a service. Simulation Modelling Practice and Theory, 34, 159-171. https://doi.org/10.1016/j.simpat.2012.03.006.

Cobos, M., Mejia, C., Bulent Ozturk, A., \& Wang, Y. (2016). A technology adoption and implementation process in an independent hotel chain. International Journal of Hospitality Management, 57, 93 105. https://doi.org/10.1016/j.ijhm.2016.06.005.

Collins, G. R., Cobanoglu, C., Bilgihan, A., \& Berezina, K. (2017). Hospitality information technology: Learning how to use it. (8th 
ed.). Dubuque, IA: Kendall/hunt publishing co. chapter 12: Automation and robotics in the hospitality industry, 413-449.

Coughlan, P., \& Coghlan, D. (2002). Action research for operations management. International Journal of Operations and Production Management, 22(2), 220-240. https://doi.org/10.1108/ 01443570210417515.

Cruz-Jesus, F., Pinheiro, A., \& Oliveira, T. (2019). Understanding CRM adoption stages: Empirical analysis building on the TOE framework. Computers in Industry, 109, 1-13. https://doi.org/10.1016/j. compind.2019.03.007.

De Keyser, A., Köcher, S., Alkire, L., Verbeeck, C., \& Kandampully, J. (2019). Frontline service technology infusion: Conceptual archetypes and future research directions. Journal of Service Management, 30(1), 156-183. https://doi.org/10.1108/JOSM-032018-0082.

Den Hertog, P., van der Aa, W., \& de Jong, M. W. (2010). Capabilities for managing service innovation: Towards a conceptual framework. Journal of Service Management, 21(4), 490-514. https://doi.org/10. $1108 / 09564231011066123$.

Dogan S., \& Vatan A. (2019). Hotel Managers' Thoughts Towards New Technologies and Service Robots' at Hotels: A Qualitative Study in Turkey. In Cobanoglu C., Cavusoglu M., \& Corbaci A. (Eds.). Advances in Global Business and Economics, 2. 382-399. https:// doi.org/10.5038/9781732127555.

Escuer, P., Mateo, A., McConnell, C., \& Schutes, J. (2014). Refining visitor tracking for museum Victoria interactive. Faculty of Worcester Polytechnic Institute: Qualifying Project Report submitted.

Hasgall, A., \& Ahituv, N. (2018). Implementing continuous adapataion to technology innovation in complex adaptive organizations. Journal of High Technology Management Research, 29, 35-45. https://doi. org/10.1016/j.hitech.2018.04.004.

Ivanov, S. (2019). Ultimate transformation: How will automation technologies disrupt the travel, tourism and hospitality industries? Zeitschrift für Tourismuswissenschaft, 11(1), 25-43.

Ivanov, S., \& Webster, C. (2017). Adoption of robots, artificial intelligence and service automation by travel, tourism and hospitality companies - a cost-benefit analysis. In International Scientific Conference "Contemporary tourism - traditions and innovations", 19-21 October 2017. Sofia: University.

Ivanov S., Webster C. (2019a) What Should Robots Do? A Comparative Analysis of Industry Professionals, Educators and Tourists. In: Pesonen J., Neidhardt J. (eds) Information and Communication Technologies in Tourism 2019. Springer, Cham. https://doi.org/10. 1007/978-3-030-05940-8 20.

Ivanov S., Webster C. (2019b) Perceived Appropriateness and Intention to Use Service Robots in Tourism. In: Pesonen J., Neidhardt J. (eds) Information and Communication Technologies in Tourism 2019. Springer, Cham. https://doi.org/10.1007/978-3-030-05940-8_19.

Ivanov, S., \& Webster, C. (2019c). Conceptual framework of the use of robots, artificial intelligence and service automation in travel, tourism, and hospitality companies. In Ivanov, S., \& Webster, C. (Eds.) Robots, Artificial Intelligence and Service Automation in Travel, Tourism and Hospitality. 7-37. https://doi.org/10.1108/978-178756-687-320191001.

Ivanov, S., \& Webster, C. (2019d). Economic fundamentals of the use of robots, artificial intelligence and service automation in travel, tourism and hospitality. In Ivanov, S., \& Webster, C. (Eds.) (2019) Robots, Artificial Intelligence and Service Automation in Travel, Tourism and Hospitality. 39-55. https://doi.org/10.1108/978-178756-687-320191002.

Ivanov, S., Webster, C., \& Berezina, K. (2017). Adoption of robots and service automation by tourism and hospitality companies. Revista Turismo \& Desenvolvimento, 27(28), 1501-1517.
Ivanov, S., Webster, C., \& Seyyedi, P. (2018). Consumers' attitudes towards the introduction of robots in accommodation establishments. Tourism, 63(3), 302-317.

Ivanov, S., Gretzel, U., Berezina, K., Sigala, M., \& Webster, C. (2019). Progress on robotics in hospitality and tourism: A review of the literature. Journal of Hospitality and Tourism Technology, 10(4), 489-521. https://doi.org/10.1108/JHTT-08-2018-0087.

Järvinen, J., \& Taiminen, H. (2016). Harnessing marketing automation for B2B content marketing. Industrial Marketing Management, 54, 164-175. https://doi.org/10.1016/j.indmarman.2015.07.002.

Kazandzhieva, V., \& Filipova, H. (2019). Customer attitudes towards robots in travel, tourism, and hospitality: A conceptual framework. In S., Ivanov, \& C., Webster (eds). Robots, artificial intelligence and service automation in travel, tourism and hospitality. Emerald Publishing. https://doi.org/10.1108/978-1-78756-687-320191004.

Kuo, C., Chen, L., \& Tseng, C. (2017). Investigating an innovative service with hospitality robots. International Journal of Contemporary Hospitality Management, 29(5), 1305-1321. https://doi.org/10. 1108/IJCHM-08-2015-0414.

Lam, C., \& Law, R. (2019). Readiness of up-scale and luxury branded hotels for digital transformation. International Journal of Hospitality Management, 79, 60-69. https://doi.org/10.1016/j. ijhm.2018.12.015.

Larivière, B., Bowen, D., Andreassen, T. W., Kunz, W., Sirianni, N. J., Voss, C., Wünderlich, N. V., \& De Keyser, A. (2017). Service encounter 2.0': An investigation into the roles of technology, employees and customers. Journal of Business Research, 79, 238-246. https://doi.org/10.1016/j.jbusres.2017.03.008.

Li, J., Bonn, M., \& Ye, B. (2019). Hotel employee's artificial intelligence and robotics awareness and its impact on turnover intention: The moderating roles of perceived organizational support and competitive psychological climate. Tourism Management, 73, 172-181. https://doi.org/10.1016/j.tourman.2019.02.006.

MacDonald, C. (2012). Understanding participatory action research: A qualitative research methodology option. The Canadian Journal of Action Research, 13(2), 34-50. https://doi.org/10.33524/cjar.v13i2. 37.

Makridakis, S. (2017). The forthcoming artificial intelligence (AI) revolution: Its impact on society and firms. Futures, 3, 1-27. https://doi. org/10.1016/j.futures.2017.03.006.

Marinova, D., de Ruyter, K., Huang, M.-H., Meuter, M. L., \& Challagalla, G. (2017). Getting smart: Learning from technologyempowered frontline interactions. Journal of Service Research, 20(1), 29-42. https://doi.org/10.1177/2F1094670516679273.

McCarthy, J. (2007). What is artificial intelligence? http://jmc.stanford. edu/articles/whatisai/whatisai.pdf.

Mori, M. (1970). The uncanny valley. Energy, 4(7), 33-35.

Murphy, D. (2018). Silver bullet or millstone? A review of success factors for implementation of marketing automation. Cogent Business \& Management, 5, 1-10. https://doi.org/10.1080/23311975.2018. 1546416.

Murphy, J., Hofacker, C., \& Gretzel, U. (2017). Dawning of the age of robots in hospitality and tourism: Challenges for teaching and research. European Journal of Tourism Research, 15, 104-111.

Murphy, J., Gretzel, U., \& Pesonen, J. (2019). Marketing robot services in hospitality and tourism: The role of anthropomorphism. Journal of Travel \& Tourism Marketing, 36(7), 784-795. https://doi.org/10. 1080/10548408.2019.1571983.

Panch, T., Szolovitz, P., \& Atun, R. (2018). Artificial intelligence, machine learning and health systems. Journal of Global Health, 8(2). https://doi.org/10.7189/2Fjogh.08.020303.

Pinillos, R., Marcosa, S., Feliz, R., Zalamab, E., \& Gómez-GarcíaBermejo, J. (2016). Long-term assessment of a service robot in a hotel environment. Robotics and Autonomous Systems, 79, 40-57. https://doi.org/10.1016/j.robot.2016.01.014. 
Qiu, H., Li, M., Shu, B., \& Bai, B. (2019). Enhancing hospitality experience with service robots: The mediating role of rapport building. Journal of Hospitality Marketing \& Management, 29(3), 1-22. https://doi.org/10.1080/19368623.2019.1645073.

Speier, C., \& Venkatesh, V. (2002). The hidden minefields in the adoption of sales force automation technologies. Journal of Marketing, 66, 98-111. https://doi.org/10.1509/2Fjmkg.66.3.98.18510.

Tung, V. W. S., \& Au, N. (2018). Exploring customer experiences with robotics in hospitality. International Journal of Contemporary Hospitality Management, 30(7), 2680-2697. https://doi.org/10. 1108/IJCHM-06-2017-0322.

Tung, V. W. S., \& Law, R. (2017). The potential for tourism and hospitality experience research in human-robot interactions. International Journal of Contemporary Hospitality Management, 29(10), 2498 2513. https://doi.org/10.1108/IJCHM-09-2016-0520.

Tussyadiah, I. (2020). A review of research into automation in tourism: Launching the annals of tourism research curated collection on artificial intelligence and robotics in tourism. Annals of Tourism Research, 81(102883), 1-13. https://doi.org/10.1016/j.annals.2020. 102883.

Tussyadiah, I. P., \& Park, S. (2018). Consumer evaluation of hotel service robots. In B. Stangl \& J. Pesonen (Eds.), Information and communication Technologies in Tourism (pp. 308-320). Cham: Springer. https://doi.org/10.1007/978-3-319-72923-7_24.

van Doorn, J., Mende, M., Noble, S. M., Hulland, J., Ostrom, A. L., Grewal, D., \& Petersen, J. A. (2017). Domo arigato Mr. Roboto: Emergence of automated social presence in organizational frontlines and Customers' Service experiences. Journal of Service Research, 20(1), 43-58. https://doi.org/10.1177/2F1094670516679272.

Wirtz, J., Patterson, P. G., Kunz, W. H., Gruber, T., Nhat Lu, V., Paluch, S., \& Martins, A. (2018). Brave new world: Service robots in the frontline. Journal of Service Management, 29(5), 907-931. https:// doi.org/10.1108/JOSM-04-2018-0119.

Yalowitz, S. S., \& Bronnenkant, K. (2009). Timing and tracking: Unlocking visitor behavior. Visitor Studies, 12(1), 47-64. https:// doi.org/10.1080/10645570902769134.

Yu, C. E. (2019). Humanlike robots as employees in the hotel industry: Thematic content analysis of online reviews. Journal of Hospitality Marketing \& Management, 29(1), 1-17. https://doi.org/10.1080/ 19368623.2019.1592733.

Publisher's note Springer Nature remains neutral with regard to jurisdictional claims in published maps and institutional affiliations. 